\title{
SEVERIDADE DA FERRUGEM-DA-FOLHA E SEUS EFEITOS SOBRE CARACTERES DA PANÍCULA DE AVEIA ${ }^{1}$
}

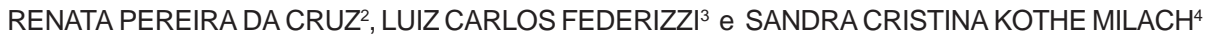

RESUMO - A ferrugem-da-folha (Puccinia coronata f.sp. avenae) foi quantificada em quatro populações $\mathrm{F}_{3}$ de aveia (Avena sativa $\mathrm{L}$.) com o objetivo de estudar a severidade dessa moléstia e seus efeitos sobre seis caracteres da panícula. As populações utilizadas foram UFRGS 881920 x UFRGS 7 , UFRGS 881920 x UFRGS 14, UFRGS 15 x UFRGS 7 e UFRGS 15 x UFRGS 14, sendo os genótipos UFRGS 881920 e UFRGS 15 resistentes à moléstia e os demais suscetíveis. A ferrugem-da-folha foi quantificada na época do florescimento, e próximo à maturação foram colhidas, em cada população, 10 plantas ao acaso por nota de ferrugem nas quais foram feitas as seguintes determinações: número de panículas, peso médio de panículas, número de grãos por planta e por panícula, peso de grãos e peso de mil grãos. A variabilidade em relação à severidade da ferrugem-da-folha foi analisada mediante a distribuição de freqüências das notas em cada população. A avaliação dos efeitos da moléstia sobre os caracteres da panícula foi feita pela análise de variância, análise de regressão polinomial e correlações fenotípicas. Os resultados obtidos demonstram haver ampla variação com respeito à severidade da moléstia nas populações estudadas, e os caracteres mais afetados foram o peso médio de panículas e o peso de mil grãos.

Termos para indexação: Avena sativa, Puccinia coronata, caracteres de rendimento.

\section{CROWN RUST SEVERITY AND ITS EFFECTS ON OAT PANICLE CHARACTERS}

\begin{abstract}
Crown rust (Puccinia coronata f.sp. avenae) was quantified in four $\mathrm{F}_{3}$ oat (Avena sativa L.) populations with the objective of studying disease severity and its effects on six panicle characters. Populations used were UFRGS 881920 x UFRGS 7, UFRGS 881920 x UFRGS 14, UFRGS 15 x UFRGS 7 and UFRGS 15 x UFRGS 14, with genotypes UFRGS 881920 and UFRGS 15 being resistant and the others susceptible. Crown rust infection was quantified at flowering stage and near grain maturity 10 plants at random were harvested per crown rust score in each population, and the following determinations were made: number of panicles, mean panicle weight, number of grains per plant and per panicle, grain weight and 1,000 grains weight. Variability for crown rust severity was analised through frequency distribution of crown rust scores in each population. Evaluation of crown rust effects on panicle characters was done through analysis of variance, polinomial regression analysis and phenotypic correlations. Results obtained demonstrate great variation for crown rust severity in the populations studied, and the most affected characters by disease occurence were mean panicle weight and 1,000 grains weight.
\end{abstract}

Index terms: Avena sativa, Puccinia coronata, yield characters.

\footnotetext{
${ }^{1}$ Aceito para publicação em 31 de julho de 1998. Extraído da dissertação de Mestrado do primeiro autor.

${ }^{2}$ Eng ${ }^{\mathrm{a}}$ Agr $\underline{\mathrm{a}}$, M.Sc., Dep. de Plantas de Lavoura, Fac. de Agronomia, UFRGS, Caixa Postal 776, CEP 91501-970 Porto Alegre, RS. Bolsista da FAPERGS. E-mail: rfcruz@cpovo.net

${ }^{3}$ Eng. Agr., Ph.D., Prof. Titular, Dep. de Plantas de Lavoura, Fac. de Agronomia, UFRGS, Pesquisador do CNPq.

${ }^{4}$ Eng $\underline{a}$ Agr ${ }^{\mathrm{a}}$, Ph.D., Prof ${ }^{-}$Adjunta, Dep. de Plantas de Lavoura, Fac. de Agronomia, UFRGS.
}

\section{INTRODUÇÃO}

A aveia é um cereal de estação fria que apresenta uma boa opção de cultivo na Região Sul do Brasil, podendo ser utilizada para produção de forragem, como cultura conservadora e recuperadora do solo e, principalmente, na alimentação humana e animal por suas excelentes propriedades nutricionais. A cariopse dos grãos de aveia contém $16-21 \%$ de pro- 
teína, sendo $86 \%$ de caseína, comparados a $60 \%$ do trigo e $48 \%$ do milho (Forsberg \& Shands, 1986).

Os programas de melhoramento genético da espécie têm atuado no desenvolvimento de cultivares com alto potencial de rendimento de grãos, porte baixo e ciclo precoce (Federizzi et al., 1988). Nesse processo foram feitas modificações na planta, tendo-se elevado a relação grão-palha, o número de grãos por panícula, a qualidade e o potencial de rendimento de grãos; o ciclo e a estatura de planta foram reduzidos, resultando num tipo agronômico de aveia mais produtivo do que o cultivado há algumas décadas (Carvalho \& Federizzi, 1989). No entanto, a ocorrência da ferrugem-da-folha (Puccinia coronata f. sp. avenae) tem limitado a expressão do potencial de rendimento dos genótipos, cuja resistência tem permanecido eficiente por poucos anos antes que o patógeno supere a mesma (Ohm \& Shaner, 1992). A moléstia tem potencial para causar severas epidemias em cultivares suscetíveis quando as condições de ambiente são favoráveis. No RS foram observadas perdas de até $50 \%$ no peso de grãos em cultivares de aveia suscetíveis à ferrugem-da-folha (Martinelli et al., 1994). Em trigo, correlações fenotípicas significativas foram obtidas entre a severidade da ferrugem-da-folha e os caracteres: rendimento de grãos $(-0,69)$, peso de mil grãos $(-0,81)$ e peso do hectolitro $(-0,83)$ (Goulart \& Paiva, 1991), comprovando a associação negativa desses caracteres com a moléstia.

A principal forma de controle da ferrugem-da-folha em aveia é mediante o uso de cultivares resistentes. Estas, porém, têm tido uma curta vida útil em virtude da grande variabilidade do patógeno, que, com o aparecimento de novas raças, quebra a resistência genética dos genótipos. No processo de melhoramento em relação à resistência é importante que se conheçam quais as características mais afetadas pela moléstia e o grau de severidade em diferentes populações, para que as populações menos afetadas possam ser selecionadas.

O objetivo do presente trabalho foi estudar a variação da severidade da ferrugem-da-folha e seus efeitos sobre caracteres relacionados ao rendimento de grãos em diferentes populações segregantes de aveia na geração $F_{3}$.

\section{MATERIAL E MÉTODOS}

Este estudo foi conduzido no ano de 1995 na Estação Experimental Agronômica da UFRGS (EEA-UFRGS) 1ocalizada na região de Eldorado do Sul, RS. O clima local, segundo a classificação de Köppen é do tipo Cfa, subtropical úmido com verão quente (Bergamaschi \& Guadagnin, 1990). O solo pertence à unidade de mapeamento São Jerônimo, classificado como Podzólico Vermelho-Escuro distrófico e tem como características boa drenagem, cor avermelhada e textura franco-argilosa (Brasil, 1973). O solo da área experimental foi preparado pelo sistema convencional (aração e gradagens) e adubado com $300 \mathrm{~kg} / \mathrm{ha}$ da fórmula 5-20-20 (N-P-K). Foram realizadas duas adubações de cobertura com $50 \mathrm{~kg} / \mathrm{ha}$ de uréia quando as plantas tinham três e seis folhas.

A semeadura foi realizada no dia $9 / 6 / 95$, sendo semeados manualmente os genitores e a geração $F_{3}$ proveniente dos cruzamentos entre os genótipos resistentes e suscetíveis. Os genitores utilizados, bem como sua genealogia e reação a campo à ferrugem-da-folha encontram-se na Tabela 1. A semeadura da geração $\mathrm{F}_{3}$ foi feita colocando-se 10 sementes por linha, de forma a permitir a avaliação individual das plantas, e mantendo-se a identificação da planta $F_{2}$ que lhe deu origem. As linhas tinham $3 \mathrm{~m}$ de comprimento e foram espaçadas em $0,30 \mathrm{~m}$. As populações utilizadas e seu respectivo número de famílias estão na Tabela 2.

$\mathrm{Na}$ época do florescimento foi feita uma quantificação da ferrugem-da-folha, dando-se notas visuais para cada planta, as quais variaram de zero (ausência de pústulas visíveis) a nove (90\% da planta apresentando sinais da moléstia), conforme a escala de Cobb modificada (Peterson et al., 1948), representando a porcentagem de área foliar total da planta atingida pela moléstia. O inóculo utilizado no experimento foi o que ocorre naturalmente no campo. No final do ciclo, próximo à maturação, foram colhidas individualmente, em cada população, 10 plantas ao acaso por nota de ferrugem nas quais foram realizadas as seguintes determinações: número de panículas, peso médio de panículas, número de grãos, número de grãos por panícula, peso de grãos e peso de mil grãos. No caso de não haver 10 plantas com determinada nota em uma população, foi colhido o número de plantas disponível, mesmo que inferior a 10. Além disso, as plantas que apresentavam sintomas de outras moléstias, como o vírus-do-nanismo-amarelo, por exemplo, não foram colhidas, de forma que a análise dos efeitos da ferrugem-da-folha sobre os caracteres da panícula foi feita com base apenas em plantas com sintomas desta moléstia. 
A partir das notas de ferrugem foram elaborados gráficos com a sua distribuição de freqüências em cada população $F_{3}$, obtida a sua média e variância. Em cada população, as notas de ferrugem foram agrupadas de forma que as inferiores 1, 2 e 3 constituíram o grupo I (resistente), as notas 4,5 e 6 o grupo II (moderadamente resistente/suscetível) e as notas 7, 8 e 9 o grupo III (suscetível). A nota zero, ou seja, ausência de moléstia não foi utilizada na análise. A caracterização dos efeitos da ferrugem-da-folha sobre os caracteres da panícula avaliados foi feita mesdiante análise de variância, análise de regressão polinomial e correlações fenotípicas.

$\mathrm{Na}$ análise de variância, os grupos de ferrugem foram considerados como variável classificatória, em delineamento completamente casualizado, sendo o número de repetições variável, dependendo do número de plantas colhidas de cada grupo. O nível de significância utilizado para o teste de $\mathrm{F}$ foi $5 \%$.

Foi realizada uma análise de regressão polinomial tendo como variável independente as notas de severidade da ferrugem e como variável dependente os seis caracteres da panícula. A significância da regressão foi testada pelo teste de F a 5\%. Foi feita também uma análise de correlação entre os caracteres da panícula e o grau de severidade da moléstia, sendo as correlações fenotípicas estimadas pela equação de Steel \& Torrie (1980).

\section{RESULTADOS E DISCUSSÃO}

\section{Severidade da ferrugem-da-folha em quatro popula- ções $F_{3}$ de aveia}

A variação encontrada em cada população estudada pode ser visualizada nas Figs. 1, 2, 3 e 4. Na população UFRGS 881920 x UFRGS 7 as notas de severidade da ferrugem-da-folha variaram de zero a 9, porém a maioria das plantas apresentou níveis altos da doença (Fig. 1). Considerando-se os três grupos distintos ou classes de ferrugem, nessa população $72,1 \%$ das plantas foram classificadas no grupo III (suscetível). Em decorrência de tal fato, a média de severidade da ferrugem observada na população foi de 6,52, com variância de 3,55.

Na população UFRGS 881920 x UFRGS 14, as notas de ferrugem variaram de zero até 7 , e ao contrário do observado na população anterior, a maioria das plantas se concentrou nas notas inferiores, com

TABELA 1. Genealogia e reação à ferrugem-da-folha de quatro genótipos de aveia utilizados no estudo dos efeitos da severidade da moléstia sobre caracteres da panícula de aveia. UFRGS, 1996.

\begin{tabular}{|c|c|c|}
\hline Genótipo parental & Genealogia & $\begin{array}{l}\text { Reação à ferrugem- } \\
\text { da-folha a campo }\end{array}$ \\
\hline UFRGS 7 & X 1205 / FLA 1093 & $\mathrm{~S}$ \\
\hline UFRGS 14 & $80 \mathrm{SA} 5 / / \mathrm{COR}^{2} / \mathrm{CTZ}^{3} /$ Pendek / Me1563 & $\mathrm{S}$ \\
\hline UFRGS 15 & $\begin{array}{l}\mathrm{COR}^{2} / \mathrm{CTZ}^{3} / \text { Pendek /Me1563 /C16 CRcpx /C } 7512 \text { / } \\
\mathrm{SR} \text { cpx / } 74 \mathrm{C} 8014\end{array}$ & $\mathrm{R}$ \\
\hline UFRGS 881920 & Sel. CP16 CRcpx / C7512 / SRcpx / 74 C 8014 & $\mathrm{R}$ \\
\hline
\end{tabular}

${ }^{1}$ S: Suscetível; R: Resistente.

TABELA 2. Número de famílias $F_{3}$ de quatro populações utilizadas no estudo dos efeitos da severidade da ferrugem-da-folha sobre caracteres da panícula de aveia. UFRGS, 1996.

\begin{tabular}{lcc}
\hline População & Número de famílias $F_{3}$ & Número total de plantas avaliadas \\
\hline UFRGS 881920 x UFRGS 7 & 45 & 256 \\
UFRGS 881920 x UFRGS 14 & 12 & 70 \\
UFRGS 15 x UFRGS 7 & 94 & 724 \\
UFRGS 15 x UFRGS 14 & 46 & 352 \\
\hline
\end{tabular}


$50 \%$ dos genótipos apresentando nota 1 no tocante à severidade da moléstia (Fig. 2). A média de severidade da ferrugem nessa população foi de 1,61 e a variância 2,50.

A população UFRGS 15 x UFRGS 7 mostrou uma ampla variação quanto à severidade da ferrugem-dafolha (Fig. 3), à semelhança da população UFRGS 881920 x UFRGS 7, com as notas variando desde zero até 9 . Considerando-se os três grupos de severidade da moléstia, tem-se que $55,4 \%$ das plantas dessa população estavam no grupo I; $28,1 \%$ estavam no grupo II e apenas $11,6 \%$ no grupo III. A média da severidade da ferrugem nessa população foi de 3,06 e a sua variância 5,75 .

A amplitude das notas de ferrugem-da-folha na população UFRGS 15 x UFRGS 14 variou de zero a 7, no entanto, a maioria das plantas apresentou notas 2, 3 e 4, correspondendo a $82,2 \%$ da população (Fig. 4). A média de ferrugem na população foi 3,20 e a variância 1,31.

A severidade da ferrugem foi bastante variável entre os genótipos genitores utilizados neste estudo, e o único deles a se apresentar suscetível foi a UFRGS 7 (Figs. 1 e 3). A classificação anterior dos genitores, a qual consta da Tabela 1 , diz respeito à presença ou ausência da ferrugem-da-folha, tendo sido considerados resistentes os genótipos que não apresentam sintomas da moléstia a campo; e suscetíveis, aqueles nos quais são observados sintomas. Neste experimento foi possível evidenciar que a cultivar UFRGS 14, apesar de ser considerada suscetível, apresenta de fato baixa severidade da moléstia, enquadrando-se no grupo I (Figs. 2 e 4). Além disso, os genótipos UFRGS 881920 e UFRGS 15, antes considerados resistentes por não apresentarem sintomas da ferrugem a campo (Tabela 1), tiveram a resistência quebrada, mostrando sintomas da moléstia, porém com baixa severidade (Figs. 1, 2, 3 e 4).

As quatro populações estudadas apresentaram grandes amplitudes de variação quanto à severidade da moléstia, no entanto, de uma forma geral pode-se dizer que as maiores amplitudes sempre foram observadas nas populações envolvendo a cultivar suscetível UFRGS 7. Possivelmente tal comportamento ocorreu em decorrência da reação contrastante deste genótipo em relação aos demais no que se refere à severidade da moléstia. As médias observadas nas populações com relação ao caráter severidade da moléstia foram relativamente baixas, com exceção da população UFRGS 881920 x UFRGS 7, na qual a maioria das plantas se concentrou no grupo III (suscetível).

A variação com respeito à severidade da ferrugem constatada nas populações é importante sob o ponto de vista do melhoramento, pois demonstra a variabilidade genética para o caráter que é liberada por meio do cruzamento de genótipos resistentes com suscetíveis. A segregação que foi obtida em todas as populações permite selecionar genótipos com diferentes níveis de resistência e, desta forma, buscar fontes promissoras de resistência parcial que venham a contribuir para aumentar a durabilidade da resistência. É interessante notar que dentro dos grupos de genitores há variabilidade no tocante à resistência e suscetibilidade, visto que nos cruzamentos foram obtidas respostas nos dois sentidos. Além disso, cabe salientar a interação dos genótipos resistentes e suscetíveis envolvidos nos cruzamentos, a qual parece ter sido mais favorável nas populações UFRGS 881920 x UFRGS 14 e UFRGS 15 x UFRGS 7 (Figs. 2 e 3 ).

\section{Influência da ferrugem-da-folha sobre diferentes caracteres da panícula}

Os caracteres da panícula foram diferentemente afetados pela ocorrência da moléstia, conforme a população. As análises de variância entre os grupos de severidade para os seis caracteres da panícula avaliados nas quatro populações encontram-se na Tabela 3.

Na população UFRGS 881920 x UFRGS 7, apenas os grupos II e III foram comparados na análise de variância, pois no grupo I não foram colhidas plantas suficientes para a análise. Houve efeito significativo da ferrugem-da-folha sobre as variáveis número de grãos por panícula e peso de mil grãos (Tabela 3), o que pode ser constatado pela significância do fator grupos na análise, mostrando que eles diferiram entre si nos dois caracteres da panícula mencionados. Já na população UFRGS 881920 x UFRGS 14, apenas os grupos I e II de severidade da moléstia foram utilizados na análise de variância, pela ausência de plantas no grupo III. Nesta população somen- 


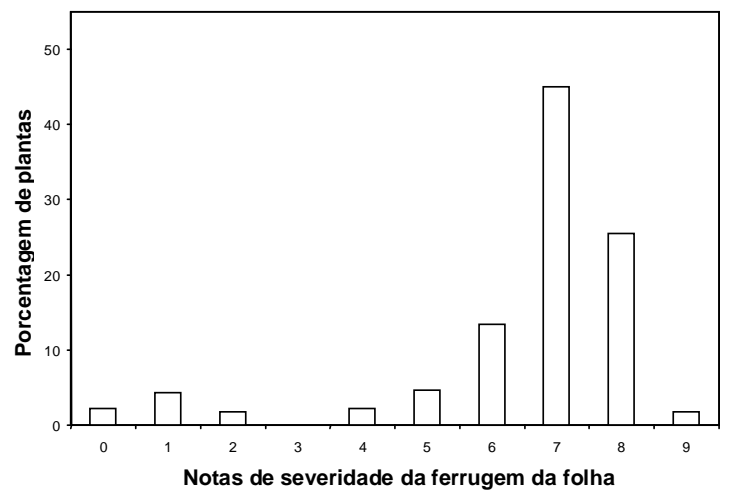

FIG. 1. Porcentagem de plantas observadas nas notas de severidade da ferrugem-da-folha na população $F_{3}$ do cruzamento UFRGS 881920 $x$ UFRGS 7. As notas 1, 2 e 3 constituem o grupo I de severidade, as notas 4, 5 e 6 o grupo II, e as notas 7,8 e 90 grupo III. Os genótipos genitores UFRGS 881920 e UFRGS 7 receberam notas 2 e 8 , respectivamente, para a severidade da moléstia. UFRGS, 1996.

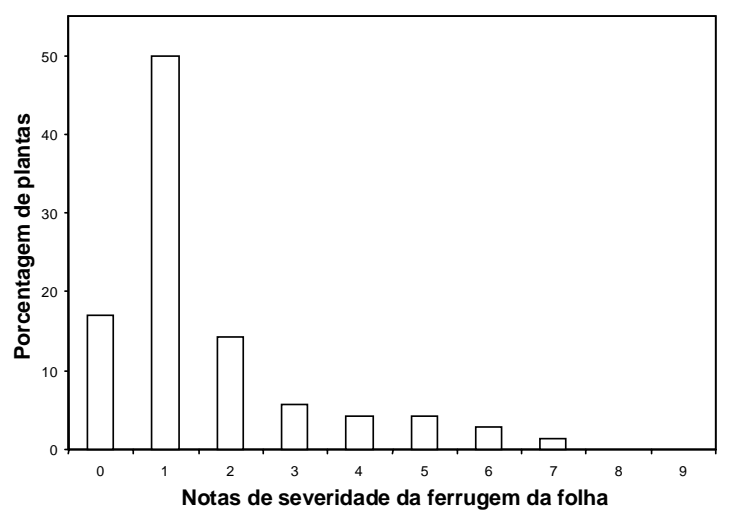

FIG. 2. Porcentagem de plantas observadas nas notas de severidade da ferrugem-da-folha na população $F_{3}$ do cruzamento UFRGS 881920 $x$ UFRGS 14. As notas 1, 2 e 3 constituem o grupo I de severidade, as notas 4, 5 e 6 o grupo II, e as notas 7, 8 e 90 grupo III. Os genótipos genitores UFRGS 881920 e UFRGS 14 receberam notas 2 e 3, respectivamente, para a severidade da moléstia. UFRGS, 1996.

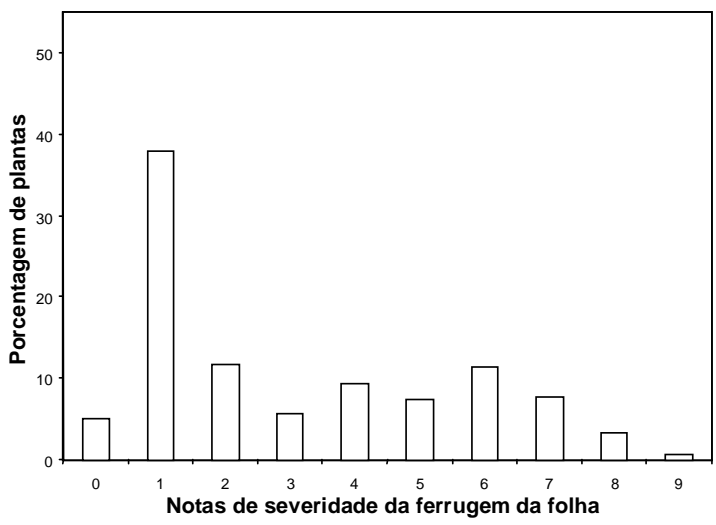

FIG.3. Porcentagem de plantas observadas nas notas de severidade da ferrugem-da-folha na população $F_{3}$ do cruzamento UFRGS 15 x UFRGS 7. As notas 1, 2 e 3 constituem o grupo I de severidade, as notas 4, 5 e 6 o grupo II, e as notas 7, 8 e 9 o grupo III. Os genótipos genitores UFRGS 15 e UFRGS 7 receberam notas 1 e 8, respectivamente, para a severidade da moléstia. UFRGS, 1996.

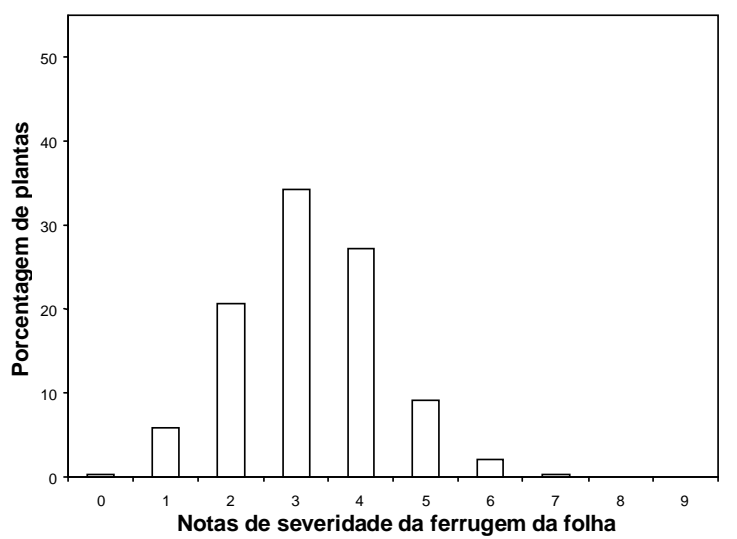

FIG. 4. Porcentagem de plantas observadas nas notas de severidade da ferrugem-da-folha na população $F_{3}$ do cruzamento UFRGS 15 x UFRGS 14. As notas 1, 2 e 3 constituem o grupo I de severidade, as notas 4, 5 e 60 grupo II, e as notas 7,8 e 90 grupo III. Os genótipos genitores UFRGS 15 e UFRGS 14 receberam notas 1 e 3, respectivamente, para a severidade da moléstia. UFRGS, 1996. 
te o peso médio de panículas foi afetado pela ferrugem-da-folha (Tabela 3), o que é comprovado pela significância do fator grupos na análise. Na população UFRGS 15 x UFRGS 7, os três grupos de severidade da ferrugem foram utilizados na análise, e todos os caracteres da panícula avaliados foram influenciados pela moléstia, com exceção do número de panículas por planta, no qual não houve diferença significativa entre os grupos (Tabela 3 ). Na população UFRGS 15 x UFRGS 14, apenas os grupos I e II de severidade da ferrugem foram utilizados na análise de variância, por não apresentar número suficiente de plantas no grupo III. Foi constatada influência da moléstia somente no que diz respeito a peso médio de panículas e o número de grãos por panícula (Tabela 3).

A análise de regressão polinomial dos seis caracteres da panícula nos diferentes níveis de severidade da ferrugem-da-folha nas quatro populações estudadas encontra-se na Tabela 4. Essa análi- se foi feita considerando-se todos os níveis de severidade observados na população em questão. De uma forma geral, os caracteres da panícula, quando afetados pela ferrugem, sofreram decréscimos lineares à medida que a severidade da moléstia aumentou. Somente no caso da população UFRGS 15 x UFRGS 14 foi observada significância da regressão quadrática para o peso de mil grãos, o qual apresentou maiores decréscimos nas notas mais elevadas de ferrugem. Esta análise permite precisar as perdas que ocorrem nos caracteres relacionados ao rendimento de grãos em função dos diferentes níveis de severidade da ferrugem-da-folha. Ela é bastante simples, podendo, assim, ser utilizada para revelar o tipo de associação existente entre a moléstia e os caracteres relacionados ao rendimento em um programa de melhoramento.

As análises de correlação fenotípica entre a severidade da ferrugem e os caracteres avaliados revelaram uma associação negativa entre a moléstia e al-

TABELA3. Quadrados médios para as variáveis número de panículas por planta (N.pan.), peso médio de panículas (P.pan.), número de grãos por planta (N.g/pl.), número de grãos por panícula (N.g/pan.), peso de grãos (P.grãos) e peso de mil grãos (P.milg.) em quatro populações $F_{3}$ de aveia. UFRGS, 1996.

\begin{tabular}{|c|c|c|c|c|c|c|c|}
\hline $\begin{array}{l}\text { Fonte de } \\
\text { variação }\end{array}$ & GL & N.pan. & P.pan. & N.g/pl. & N.g/pan. & P.grãos & P.milg. \\
\hline & \multicolumn{7}{|c|}{ População UFRGS 881920 x UFRGS 7} \\
\hline Grupos & 1 & 106,5 & 0,2 & 9037,6 & $1583,4^{*}$ & 61,6 & $118,9^{*}$ \\
\hline Resíduo & 36 & 73,0 & 0,2 & 188008,2 & 307,2 & 87,9 & 9,3 \\
\hline \multirow[t]{2}{*}{$\mathrm{CV}(\%)$} & & 48,7 & 31,2 & 46,6 & 31,7 & 49,1 & 15,1 \\
\hline & \multicolumn{7}{|c|}{ População UFRGS 881920 x UFRGS 14} \\
\hline Grupos & 1 & 33,7 & $0,8^{*}$ & 634871,8 & 606,1 & 124,4 & 13,0 \\
\hline Resíduo & 21 & 83,6 & 0,1 & 424079,1 & 171,7 & 78,3 & 24,9 \\
\hline \multirow[t]{2}{*}{$\mathrm{CV}(\%)$} & & 44,8 & 18,1 & 50,2 & 20,9 & 28,6 & 19,1 \\
\hline & \multicolumn{7}{|c|}{ População UFRGS 15 x UFRGS 7} \\
\hline Grupos & 2 & 48,8 & $4,7^{*}$ & $1390967,4^{*}$ & $2078,3^{*}$ & $847,0^{*}$ & $85,6^{*}$ \\
\hline Resíduo & 81 & 37,1 & 0,3 & 324989,8 & 321,8 & 92,5 & 6,8 \\
\hline \multirow[t]{2}{*}{$\mathrm{CV}(\%)$} & & 40,6 & 31,9 & 50,5 & 24,3 & 44,0 & 13,4 \\
\hline & \multicolumn{7}{|c|}{ População UFRGS 15 x UFRGS 14} \\
\hline Grupos & 1 & 0,9 & $1,9^{*}$ & 430084,5 & $2844,5^{*}$ & 29,4 & 9,2 \\
\hline Resíduo & 56 & 39,6 & 0,4 & 259928,0 & 453,8 & 101,0 & 9,6 \\
\hline CV (\%) & & 36,6 & 33,4 & 42,0 & 29,6 & 39,1 & 13,9 \\
\hline
\end{tabular}


guns deles, dependendo da população. Os resultados referentes às correlações fenotípicas, em cada população, encontram-se na Tabela 5 .

Com base nas três análises feitas, tem-se que na população UFRGS 881920 x UFRGS 7 o peso de mil grãos foi o caráter mais influenciado pela ferrugemda-folha, tendo sido significativo quanto aos grupos (Tabela 3), na análise de regressão (Tabela 4) e, de acordo com a análise de correlação foi bastante dependente da moléstia (Tabela 5). O caráter da panícula mais afetado pela ocorrência da ferrugemda-folha na população UFRGS 881920 x UFRGS 14 foi o peso médio de panículas. Ele foi o único a apresentar diferença significativa entre os grupos de severidade (Tabela 3 ) e foi negativamente associado à moléstia como pode ser verificado pela significância da regressão linear (Tabela 4) e pela correlação fenotípica (Tabela 5). Já na população UFRGS 15 x UFRGS 7, apenas o número de panículas por planta não foi afetado pela ferrugem. Entre os demais caracteres, o peso médio de panículas e o peso de mil grãos foram os mais afetados, o que pode ser comprovado por suas correlações fenotípicas com a severidade da ferrugem (Tabela 5). Os caracteres que sofreram decréscimos significativos em função da severidade da moléstia na população UFRGS 15 x UFRGS 14 foram o peso médio de panículas e o número de grãos por panícula, como pode ser observado pela análise da variância (Tabela 3), análise de regressão (Tabela 4) e dos coeficientes de correlação fenotípica com a moléstia (Tabela 5).

TABELA4. Equações de regressão estimadas para descrever a relação entre a severidade da ferrugem-dafolha e o número de panículas por planta (N.pan.), peso médio de panículas (P.pan.), número de grãos por planta (N.g/pl.), número de grãos por panícula (N.g/pan.), peso de grãos (P.grãos) e peso de mil grãos (P.milg.) em quatro populações $F_{3}$ de aveia. UFRGS, 1996.

\begin{tabular}{|c|c|c|c|c|c|c|c|c|}
\hline \multirow[t]{2}{*}{ Variável } & \multicolumn{2}{|c|}{$\mathrm{U} 881920 \times \mathrm{U}^{1}$} & \multicolumn{2}{|c|}{ U881920 x U14 } & \multicolumn{2}{|c|}{$\mathrm{U} 15 \times \mathrm{U} 7$} & \multicolumn{2}{|l|}{$\mathrm{U} 15 \times \mathrm{U} 14$} \\
\hline & Equação & $\mathrm{R}^{2}$ & Equação & $\mathrm{R}^{2}$ & Equação & $\mathrm{R}^{2}$ & Equação & $\mathrm{R}^{2}$ \\
\hline N.pan. & $\mathrm{ns}^{+}$ & ns & $\mathrm{ns}$ & $\mathrm{ns}$ & $\mathrm{ns}$ & ns & ns & ns \\
\hline P.pan. & $\mathrm{ns}$ & ns & $y=2,5-0,2 x$ & $0,67^{*}$ & $y=2,6-0,1 x$ & $0,91^{*}$ & $y=2,8-0,2 x$ & $0,73^{*}$ \\
\hline N.g/pl. & ns & ns & $\mathrm{ns}$ & $\mathrm{ns}$ & $y=1464,1-70,8 x$ & $0,66^{*}$ & $\mathrm{~ns}$ & $\mathrm{~ns}$ \\
\hline N.g/pan. & $\mathrm{ns}$ & ns & $y=70,3-4,1 x$ & $0,59^{*}$ & $y=87,3-2,9 x$ & $0,81^{*}$ & $y=96,9-8 x$ & $0,78^{*}$ \\
\hline P.grãos & ns & ns & $\mathrm{ns}$ & $\mathrm{ns}$ & $y=30,5-1,8 x$ & $0,85^{*}$ & $\mathrm{~ns}$ & $\mathrm{~ns}$ \\
\hline P.milg. & $y=30,1-1,6 x^{++}$ & $0,84 *$ & $\mathrm{~ns}$ & $\mathrm{~ns}$ & $y=22,2-0,6 x$ & $0,87^{*}$ & $y=17,1+3,5 x-0,5 x^{2}$ & $0,76^{*}$ \\
\hline
\end{tabular}

${ }^{1} \mathrm{U}$ : UFRGS

* Significativo a $5 \%$ de probabilidade.

${ }^{+}$Não significativo a $5 \%$ de probabilidade.

${ }^{++} \mathrm{x} \therefore 0 \leq \mathrm{x} \leq 9$

TABELA 5. Correlações fenotípicas entre a severidade da ferrugem-da-folha e o número de panículas por planta (N.pan.), peso médio de panículas (P.pan.), número de grãos por planta (N.g/pl.), número de grãos por panícula (N.g/pan.), peso de grãos (P.grãos) e peso de mil grãos (P.milg.) em quatro populações $F_{3}$ de aveia. UFRGS, 1996.

\begin{tabular}{lcccccc}
\hline População & N.pan. & P.pan. & N.g/pl. & N.g/pan. & P.grãos & P.milg. \\
\hline U881920 x U7 & $-0,32^{*}$ & 0,06 & $-0,07$ & $0,37^{*}$ & $-0,29$ & $-0,73^{*}$ \\
U881920 x U14 & $-0,20$ & $-0,58^{*}$ & $-0,41^{*}$ & $-0,55^{*}$ & $-0,41^{*}$ & 0,31 \\
U15 x U7 & $-0,17$ & $-0,48^{*}$ & $-0,30^{*}$ & $-0,36^{*}$ & $-0,43^{*}$ & $-0,49^{*}$ \\
U15 x U14 & 0,05 & $-0,35^{*}$ & $-0,23$ & $-0,43^{*}$ & $-0,17$ & 0,13 \\
\hline
\end{tabular}

1 U: UFRGS.

* Significativo a $5 \%$ de probabilidade. 
Em termos gerais, observou-se que o número de caracteres afetados pela ferrugem-da-folha, em cada população, foi mais relacionado ao genótipo genitor suscetível envolvido no cruzamento do que ao resistente. Assim, um maior número de caracteres foi afetado quando a cultivar UFRGS 7 foi o genótipo suscetível envolvido no cruzamento; enquanto quando foi a UFRGS 14, menos caracteres sofreram influência por parte da ferrugem-da-folha. Também pode ser notado que, nas duas populações em que a UFRGS 14 estava presente, os caracteres mais afetados pela moléstia sempre foram o peso médio de panículas e o número de grãos por panícula. Já no caso da UFRGS 7, em seu cruzamento com a UFRGS 15 foram constatadas perdas em quase todos os caracteres estudados, o que contrasta com o observado no seu cruzamento com a UFRGS 881920, em que o peso de mil grãos foi a variável mais influenciada pela moléstia.

Vários autores constataram perdas em componentes do rendimento e caracteres de importância agronômica em aveia pela ocorrência da ferrugem-da-folha (Singleton et al., 1979; Reis \& Beviláqua, 1996; Thomé et al., 1996). No entanto, poucos foram os estudos que relacionaram diferentes níveis de severidade com caracteres relacionados ao rendimento de grãos, como foi feito por Bissonnette et al. (1994). Eles propuseram um modelo de regressão linear para explicar a queda no rendimento de grãos e no peso do hectolitro em função do aumento nos níveis de severidade da ferrugem. Outros autores correlacionaram perdas em caracteres de importância agronômica com moléstias como as ferrugens-da-folhado-trigo (Goulart \& Paiva, 1991) e do milheto (Wilson et al., 1994). Este último observou, ainda, que a significância das correlações entre os caracteres e a moléstia dependeu da intensidade desta. Os valores de correlação obtidos no presente trabalho foram calculados com base em todos os níveis de severidade observados nas populações, e apesar de não terem apresentado magnitudes elevadas, foram significativos, demonstrando a influência indireta da severidade da ferrugem sobre as características estudadas. Cabe destacar que as avaliações foram feitas em plantas individuais, o que não é ideal para se pesquisar perdas em caracteres relacionados ao rendimento de grãos pela ocorrência da moléstia. Tal procedimento foi adotado pela necessidade de se realizarem leituras individuais nas plantas, uma vez que se estava trabalhando com populações segregantes.

\section{CONCLUSÕES}

1. As grandes amplitudes de variação com respeito ao caráter severidade da ferrugem-da-folha nas populações estudadas permitem a seleção de genótipos com diferentes níveis de resistência.

2. As perdas nos caracteres da panícula causadas pela ferrugem-da-folha são dependentes da população.

3. Os caracteres da panícula mais afetados pela severidade da ferrugem-da-folha são o peso médio de panículas e o peso de mil grãos.

\section{REFERÊNCIAS}

BERGAMASCHI, H.; GUADAGNIN, M.R. Agroclima da Estação Experimental Agronômica: UFRGS. Porto Alegre: UFRGS, 1990. 60p.

BISSONNETTE, S.M.; D'ARCY, C.J.; PEDERSEN, W.L. Yield loss in two spring oat cultivars due to Puccinia coronata f.sp. avenae in the presence or absence of barley yellow dwarf virus. Phytopathology, St. Paul, v.84, n.4, p.363-371, 1994.

BRASIL. Ministério da Agricultura. Levantamento e reconhecimento dos solos do Estado do Rio Grande do Sul. Recife, 1973. p.163. (MA. Boletim Técnico, 30).

CARVALHO, F.I.F.; FEDERIZZI, L.C. Evolução da cultura da aveia no sul do Brasil. Trigo e Soja, Porto Alegre, n.102, p.16-19, 1989.

FEDERIZZI, L.C.; CARVALHO, F.I.F.; TELLI, M. Comparison of two selection strategies for the development of high-yielding oat varieties in Brazil. In: INTERNATIONAL OAT CONFERENCE, 3. 1988, Lund. Proceedings..., Lund: Svalöf AB, 1988. p.122-127.

FORSBERG, R.A.; SHANDS, H.L. Oat Breeding. Critical Science Review, v.5, p.167-207, 1986.

GOULART, A.C.P.; PAIVA, F. de A. Avaliação de fungicidas no controle das ferrugens do trigo. Pes- 
quisa Agropecuária Brasileira, Brasília, v.26, n.11/12, p.1975-1981, 1991.

\section{MARTINELLI, J.A.; FEDERIZZI, L.C.; BENNEDETTI,} A.C. Redução do rendimento de grãos da aveia em função da severidade da ferrugem da folha. Summa Phytopathologica, Jaguariúna, v.20, n.2, p.116-118, 1994.

OHM, H.W.; SHANER, G. Breeding oat for resistance to diseases. In: MARSHALL, H.G.; SORRELLS, M.E. (Eds.). Oat Science and Technology. Madison: American Society of Agronomy and Crop Science of America, 1992. p.657-698.

PETERSON, R.F.; CAMPBELL, A.B.; HANNAH, A.E. A diagrammatic scale for estimating rust intensity of leaves and stem of cereals. Canadian Journal of Research. Section C. Botanical Science, Ottawa, v.26, p.496-500, 1948.

REIS, E.M.; BEVILÁQUA, L.C. Relação entre a incidência da ferrugem da folha, causada por Puccinia coronata f.sp. avenae, e o rendimento de grãos de aveia cv. UPF13, em Passo Fundo, 1995. In: REUNIÃO DA COMISSÃO SULBRASILEIRA DE
PESQUISA DE AVEIA, 16., 1996, Florianópolis. Resultados experimentais... Florianópolis: UFSCCSPA, 1996. p.239-240.

SINGLETON, L.L.; STUTHMAN, D.D.; MOORE, M.B. Effect of crown rust on oat groat protein. Phytopathology, St. Paul, v.69, n.7, p.776-778, 1979.

STEEL, R.G.D.; TORRIE, J.L. Principles and procedures of statistics. 2.ed. New York: McGraw-Hill, 1980. 418p.

THOMÉ, G.C.H.; CABRAL, C.B.; BOTHONA, C.R.A.; FASSINA, P.E.M.; FEDERIZZI, L.C.; MILACH, S.C.K. Efeitos da ferrugem da folha sobre caracteres de importância agronômica em genótipos de aveia com diferentes tipos de reação à doença. In: REUNIÃO DA COMISSÃO SULBRASILEIRA DE PESQUISA DE AVEIA, 16., 1996, Florianópolis. Resultados experimentais... Florianópolis: UFSC-CSPA, 1996. p.54-56.

WILSON, J.P.; HANNA, W.W.; GATES, R.N. Stability of forage yield and quality in pearl millet hybrids heterogeneous for rust resistance. Euphytica, Wageningen, v.72, n.3, p.163-170, 1994. 